\title{
Knowledge, Attitude and Awareness of Hazards Associated with Use of Cotton Bud in a Nigerian Community
}

\author{
Olajide Toye Gabriel1* ${ }^{*}$ Usman Aminu Mohammed², Eletta Adebisi Paul² \\ ${ }^{1}$ Department of Ear, Nose and Throat Surgery, Federal Teaching Hospital, Ido Ekiti, Nigeria \\ ${ }^{2}$ Department of Ear, Nose and Throat Surgery, Federal Medical Centre, Bida, Nigeria \\ Email: toyeolajide@yahoo.co.uk, 2mausman@gmail.com, elettaadebisi@yahoo.com
}

Received 7 April 2015; accepted 18 May 2015; published 21 May 2015

Copyright $(2015$ by authors and Scientific Research Publishing Inc.

This work is licensed under the Creative Commons Attribution International License (CC BY).

http://creativecommons.org/licenses/by/4.0/

(c) (i) Open Access

\begin{abstract}
Background: Self-cleaning of ears with a cotton bud is a common practice, and the hazards associated with such action are well documented. The aim of this study is to find out the knowledge, attitude and awareness on the use of cotton buds among the people of Bida community. Design and Methodology: It is a community based cross sectional descriptive study carried out among people of Bida community. Subjects were selected by multistage sampling technique. Pre-tested semi-structured questionnaires were used to collect data from 278 young adults and adults' respondents. Results: There were a total number of 278 responses out of 290 respondents interviewed (M:F = 1:1.03). Age range was from 18 to 65 years with a mean of $29.64 \pm 10.06 \mathrm{SD}$. The highest response was in the age group of $20-29$ years. About $72.3 \%$ of the respondents had tertiary education, and $40.3 \%$ were civil servants. Majority $(92.8 \%)$ of the respondents had indulged in the use of cotton buds to clean their ears. Most (57.8\%) of those that had used cotton buds did so because of itching in the ears. Only $44.9 \%$ of respondents agreed that cotton buds could cause damage to the ears. Many (61.2\%) believed that there was benefit of using cotton buds in cleaning the ears. Majority of the respondents $(\mathbf{7 4 . 1 \%}$ ) had not got information on the danger of using cotton bud in cleaning their ears. Conclusion: From our data in this study, majority of the subjects had indulged in the use of cotton bud in cleaning their ears. And the commonest reason for using cotton buds is due to itching in the ears. Their Knowledge, attitude and awareness to the use of cotton buds are very poor with erroneous believe that there is benefit to its use. There is a need to increase awareness by public enlightenment and health education and to establish school health programme in our various schools.
\end{abstract}

\section{Keywords}

Knowledge, Awareness, Hazards, Cotton Bud, Nigerian Community

\footnotetext{
${ }^{*}$ Corresponding author.
}

How to cite this paper: Olajide, T.G., Usman, A.M. and Eletta, A.P. (2015) Knowledge, Attitude and Awareness of Hazards Associated with Use of Cotton Bud in a Nigerian Community. International Journal of Otolaryngology and Head \& Neck Surgery, 4, 248-253. http://dx.doi.org/10.4236/ijohns.2015.43042 


\section{Introduction}

Cotton buds or cotton swabs consist of a small wad of cotton wrapped around one or both ends of a short rod, usually made of either wood, rolled paper, or plastic [1]. The cotton swab was invented in 1923 by Leo Gersternzang who observed his wife to have attached wads of cotton on toothpicks to clean his baby's ear [2]. Cleaning of ears with a cotton bud is a common practice which can traumatize the ear canal and such ear injuries are commonly seen in ENT practice [3] [4]. The primary reason (96\%) given in one study for using cotton buds was to remove ear wax [5]. However, it is known that ear wax is produced in the outer part of the canal and migrates out with the epithelium toward the pinna. These objects are cheap and readily available from drug stores and super markets. Cotton bud tips are not only used by adults, but also commonly used in pediatric population either by children themselves or by parents [6]. Insertion of cotton buds inside ears is not only unnecessary but also potentially dangerous and has widely been condemned worldwide by otolaryngologists. This is due to well documented complications, including trauma, impacted ear wax, infection and retention of the cotton bud [7] [8]. Little studies have been conducted on the usage of cotton bud in Nigeria. We therefore decided to carry out this study in a community to find out their knowledge, attitude and awareness on the hazards of using cotton bud.

\section{Design \& Methodology}

This is a community based descriptive study carried out among young adults and adults' residents of Bida, over a 4 weeks period between October and November, 2014. Bida is an urban settlement/town in the north central Nigeria, the capital city of the Nupe Kingdom and headquarter of Bida Local Government Area of Niger State. It is multicultural population comprising all the ethnic groups of Nigeria and people of all walks of life with an estimated population of about 185,553 people. All social classes in the society are well represented in the community. Subjects were selected from the social strata (market, schools/colleges and federal institutions) including the artisan by multistage sampling technique. Pre-tested semi-structured questionnaires were used as instrument of data collection and these were self administered. The questionnaires contained information on bio-data, knowledge, attitude and awareness of respondents towards usage of cotton bud, among others. It was not labeled in order to ensure confidentiality. Inclusion criteria were subjects that were 18 years and above and also having given consent to participate in the study. Approval to carry out the study was given by the ethical and research committee of the hospital. A simple descriptive analysis of the data obtained was carried out using SPSS version 15.0 , and the results were presented in simple tables and charts.

\section{Results}

A total of 278 out of the 290 questionnaires that was administered were returned representing a $95.7 \%$ response rate. The male respondents were $137(49.3 \%)$ while the female's was $141(50.7 \%)$ given a male to female ratio of 1:1.03. Their age ranged was from 18 years to 65 years with a mean of $29.64 \pm 10.06 \mathrm{SD}$. From Table 1, the highest response was in the age group of 20 - 29 years representing $51.1 \%$ of the respondents. Majority (50.4\%) of the respondents were Nupe by tribe. One hundred and forty one $(50.7 \%)$ were Christian, while 137 (49.3\%) practice Islamic religion. Two hundred and one (72.3\%) had tertiary education, $56(20.1 \%)$ had secondary, 10 (3.6\%) had primary while $11(4.0 \%)$ had no formal education (Figure 1). One hundred and twelve $(40.3 \%)$ of the respondents were civil servants, $99(35.6 \%)$ were students, $32(11.5 \%)$ engaged in business, $19(6.8 \%)$ were farmer, $13(4.7 \%)$ were artisan while $11(4.0 \%)$ had no job. Two hundred and fifty eight $(92.8 \%)$ of the respondents had used cotton bud in cleaning their ears, $17(6.1 \%)$ had never used it while $3(1.1 \%)$ were not sure. Out of those that use cotton buds to clean their ears, majority (57.8\%) of them used it because of itching in the ear (Figure 2). One hundred and thirty eight (53.5\%) respondents used cotton buds on their own, $89(34.5 \%)$ were introduced to it by their parents, $15(5.8 \%)$ by health care provider, $12(4.7 \%)$ by friends while $4(1.6 \%)$ from their spouses. On whether the cotton bud can damage the ear, $123(44.9 \%)$ of the respondents said yes, 77 $(28.1 \%)$ said no while $74(27.0 \%)$ were not sure. One hundred and seventy $(61.2 \%)$ respondents believed that there is benefit from cleaning the ears with cotton bud, 61(21.9\%) said there is no benefit of using it, while 47 $(16.9 \%)$ were not sure if there is any benefit. Only Fifty eight $(22.5 \%)$ of the respondents that uses cotton bud developed complications, $190(73.6 \%)$ had no complication and $10(3.9 \%)$ were not sure. Two hundred and six (74.1\%) of the subjects had no information on the danger of using cotton buds in the ears, while only $72(25.9 \%)$ 
Table 1. Showing age, gender and socio-demographic characteristics of respondents. $N=278$.

\begin{tabular}{|c|c|c|c|}
\hline Category & & Frequency (N) & Percent (\%) \\
\hline \multirow[t]{7}{*}{ Age group (years) } & $10-19$ & 21 & 7.6 \\
\hline & $20-29$ & 142 & 51.1 \\
\hline & $30-39$ & 69 & 24.8 \\
\hline & $40-49$ & 32 & 11.5 \\
\hline & $50-59$ & 6 & 2.2 \\
\hline & $60-69$ & 8 & 2.9 \\
\hline & & 278 & 100.0 \\
\hline \multirow[t]{3}{*}{ Gender } & Male & 137 & 49.3 \\
\hline & Female & 141 & 50.7 \\
\hline & & 278 & 100.0 \\
\hline \multirow[t]{5}{*}{ Tribe } & Yoruba & 65 & 23.4 \\
\hline & Hausa & 42 & 15.1 \\
\hline & Ibo & 31 & 11.2 \\
\hline & Nupe & 140 & 50.4 \\
\hline & & 278 & 100.0 \\
\hline \multirow[t]{3}{*}{ Religion } & Christianity & 141 & 50.7 \\
\hline & Islam & 137 & 49.3 \\
\hline & & 278 & 100.0 \\
\hline \multirow[t]{5}{*}{ Education } & Nil & 11 & 4.0 \\
\hline & Primary & 10 & 3.6 \\
\hline & Secondary & 56 & 20.1 \\
\hline & Tertiary & 201 & 72.3 \\
\hline & & 278 & 100.0 \\
\hline
\end{tabular}

have information. Of those that had information, 51 (18.3\%) of them got their information from health talk through the health workers in the hospital, 13 (4.7\%) got information from their friends and neighbours, 7 (2.5\%) through Radio/TV while only one (0.4\%) subject had information from publications (Table 2).

\section{Discussion}

Cotton-bud-related injuries are a common reason for attendance at ear, nose and throat (ENT) referral clinics [3]. The response rate of $95.7 \%$ (278/290) from our subjects in this study was good and showed their willingness to take part in the study. This study also showed that Females' respondents were slightly higher than their male counterpart, in contrast to separate studies done by Hobson and Kumar et al. [4] [6], where they recorded male preponderance. However another study done by Lee et al. [8] did not showed any gender difference. The highest users of cotton buds in this study were in the age group $20-29$ years. Similar findings were recorded in other studies [8] [9]. Despite the fact that majority of our respondents (72.3\%) were literate, larger percentage (92.8\%) of them had used cotton buds to clean their ears. This is similar to other studies [8] [10] [11]. There were various reasons why people clean their ears with cotton buds; in this study the commonest reason is to scratch itchy ear canals in $57.8 \%$ of the respondents. This is in contrast to other studies where most subjects used cotton buds to 


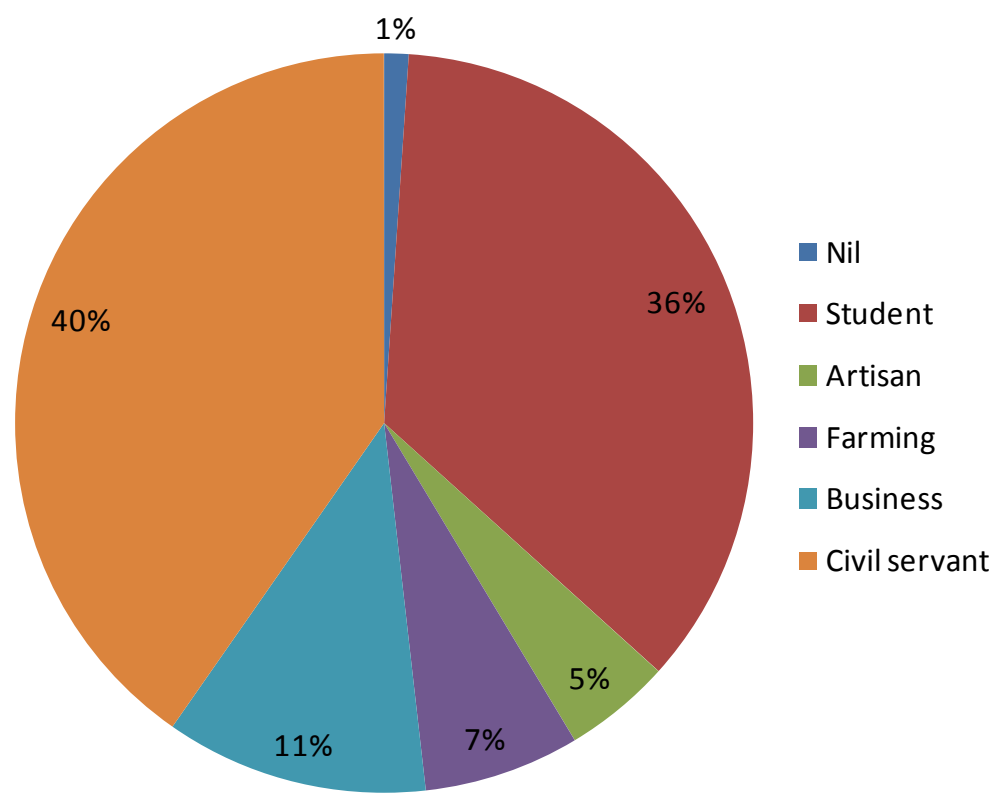

Figure 1. Occupation of respondents.

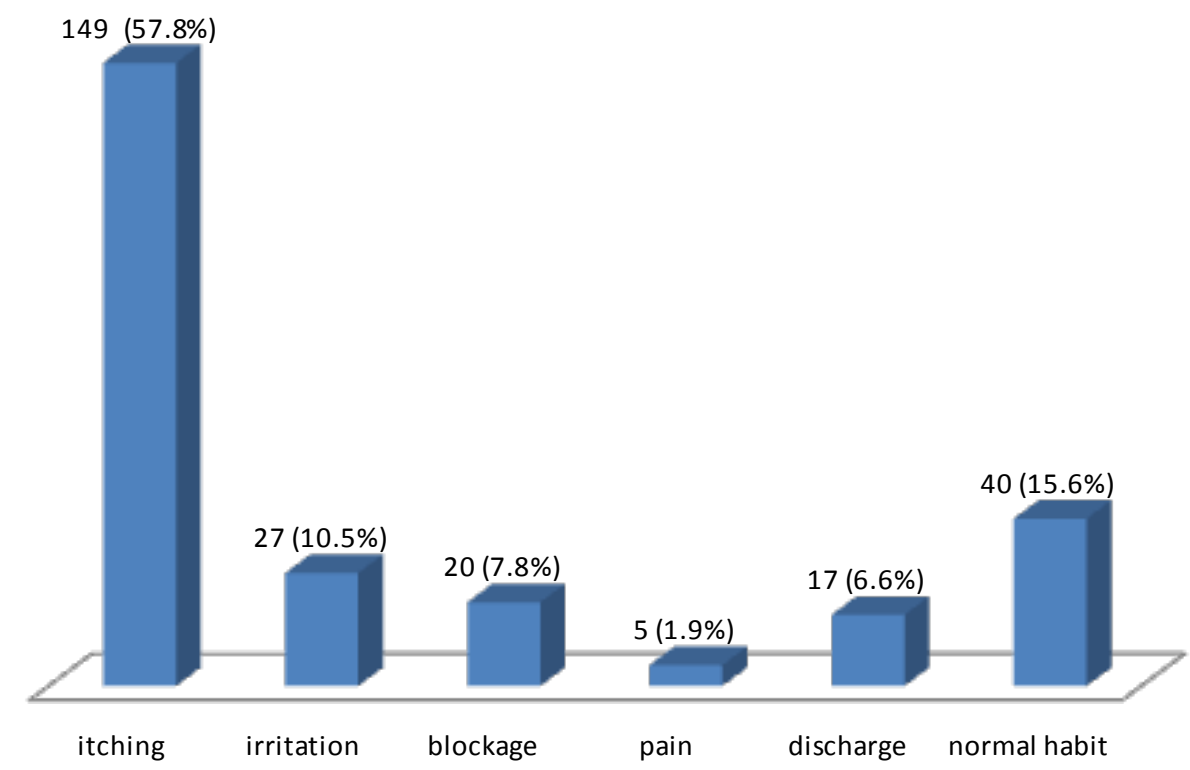

Figure 2. Reasons for cleaning ears with cotton buds.

remove wax in their ear canals [8]-[10]. The practice of using cotton bud to scratch ear canal is dangerous, as it can easily traumatize the ear canal and infection may eventually follows. Medical opinion should be sought from Otolaryngologist if ear itchiness persists, as this may be a symptom of otomycosis or eczema. Of worthy mention are those that make use of cotton bud as part of their normal/routine habit on daily basis not minding the consequences that followed it use. Majority $(53.5 \%)$ of the respondents in this study used cotton buds on their own $a b$ initio. however some of them imitate their parents, spouses and friends who also practiced the habit. About 5.8\% claimed to have conceived the idea from health care workers. Hobson et al. also reported that only small numbers of his subjects were advised to use cotton bud by medical professionals [4]. This study also showed that majority (61.2\%) of our respondents believed that there were benefits in using cotton bud hence only few (44.9\%) them think that using cotton bud can cause damage to ears. Some of the respondents also claimed that apart from aesthetic appearance of cotton buds, the tip are softer and safer to use than the matches 
Table 2. Showing the participants knowledge, attitude and awareness to the uses, damage, complications, benefits and source of information on the usage of cotton buds.

\begin{tabular}{|c|c|c|}
\hline Category & Frequency $(\mathrm{N})$ & Percent $(\%)$ \\
\hline \multicolumn{3}{|c|}{ Uses cotton bud } \\
\hline Yes & 258 & 92.8 \\
\hline No & 17 & 6.1 \\
\hline Not sure & 3 & 1.1 \\
\hline \multicolumn{3}{|c|}{ Whether cotton bud can damage ear } \\
\hline Yes & 123 & 44.9 \\
\hline No & 77 & 28.1 \\
\hline Not sure & 74 & 27.1 \\
\hline \multicolumn{3}{|c|}{ Benefits of using cotton bud } \\
\hline Yes & 170 & 61.2 \\
\hline No & 61 & 21.9 \\
\hline Not sure & 47 & 16.9 \\
\hline \multicolumn{3}{|c|}{ Complications from use of cotton bud } \\
\hline Yes & 58 & 22.5 \\
\hline No & 190 & 73.6 \\
\hline Not sure & 10 & 3.9 \\
\hline \multicolumn{3}{|c|}{ Information on use of cotton bud } \\
\hline No information & 206 & 74.1 \\
\hline Had information & 72 & 25.9 \\
\hline Health talk in the hospital & \multicolumn{2}{|c|}{$51(18.3 \%)$} \\
\hline Friends/neighbour & \multicolumn{2}{|c|}{$13(4.7 \%)$} \\
\hline Media (radio/TV) & \multicolumn{2}{|c|}{$7(2.5 \%)$} \\
\hline Publication/journal & \multicolumn{2}{|c|}{$1(0.4 \%)$} \\
\hline
\end{tabular}

or broom stick which they noted to be sharp. In this study complication noted includes bruises with minor bleeding, otalgia and impaction of the cotton bud in the EAC leading to blockage. Otitis externa has been reported by overzealous use of cotton buds in some studies [8] [12]. Most (74.1\%) of our respondents had never had information on the dangers of using cotton buds in the ears. This shows that the medical advice not to clean the ears is not widely known as also noted in a study done by Olaosun [10]. Of the few subjects that had the information, only $18.3 \%$ got their information in the hospital through health talk from health workers. It is glaring that awareness is very poor. Most of the subjects that use cotton buds were young adults, and this practice will continue as they teach their children to do this. There is need to create awareness among people in the community and in the schools through health education with emphasis that ear wax should not be removed with cotton buds. There is a natural mechanism where ear wax is removed from the ear canal.

\section{Conclusion}

In this study, majority (92.8\%) of our participants indulged in the use of cotton buds in cleaning their ears. And the commonest reason for using cotton bud is due to itching in the ears. Their knowledge, attitude and awareness to the use of cotton buds are very poor with erroneous believe that there is benefit to its use. The medical advice 
not to clean the ears is not widely known. There is a need to increase awareness by public enlightenment and health education and to establish school health programme in our various schools.

\section{References}

[1] http://en.wikipedia.org/wiki/cotton_swab

[2] http://en.wikipedia.org/wiki/Leo_Gerstenzang

[3] Steele, B.D. and Brennan, P.O. (2002) A Prospective Survey of Patients with Presumed Accidental Ear Injury Presenting to a Paediatric Accident and Emergency Department. Emergency Medicine Journal, 19, 226-228.

[4] Hobson, J.C. and Lavy, J.A. (2005) Use and Abuse of Cotton Buds. Journal of the Royal Society of Medicine, 98 , 360-361. http://dx.doi.org/10.1258/jrsm.98.8.360

[5] Nagala, S., Singh, P. and Tostevin, P. (2011) Extent of Cotton-Bud Use in Ears. British Journal of General Practice, 61, 662-663. http://dx.doi.org/10.3399/bjgp11X606546

[6] Kumar, S. and Ahmed, S. (2008) Use of Cotton Buds and Its Complications. Journal of Surgery Pakistan (International), 13, 137-138

[7] Raman, R. (1997) Should Cotton Buds Be Banned? Tropical Doctor, 27, 250.

[8] Amutta, S.B., Yunusa, M.A., Iseh, K.R., Obembe, A., Egili, E., Aliyu, D. and Abdullahi, M. (2013) Sociodemographic Characteristics and Prevalence of Self Ear Cleaning in Sokoto Metropolis. International Journal of Otolaryngology and Head \& Neck Surgery, 2, 276-279.

[9] Lee, L.M., Govindaraju, R. and Hon, S.K. (2005) Cotton Bud and Ear Cleaning-A Loose Tip Cotton Bud? Medical Journal of Malaysia, $\mathbf{6 0}, 85-88$.

[10] Olaosun, A.O. (2014) Self-Ear-Cleaning among Educated Young Adults in Nigeria. Journal of Family Medicine and Primary Care, 3, 17-21. http://dx.doi.org/10.4103/2249-4863.130262

[11] Afolabi, A.O., Kodiya, A.M., Bakari, A. and Ahmad, B.M. (2009) Attitude of Self Ear Cleaning in Black Africans: Any Benefit? East African Journal of Public Health, 6, 43-46. http://dx.doi.org/10.4314/eajph.v6i1.45743

[12] Nussinovitch, M., Rimon, A., Volovitz, B., Raveh, E., Prais, D. and Amir, J. (2004) Cotton-Tip Applicators as Aleading Cause of Otitis Externa. International Journal of Pediatric Otorhinolaryngology, 68, 433-435. http://dx.doi.org/10.1016/j.ijporl.2003.11.014 